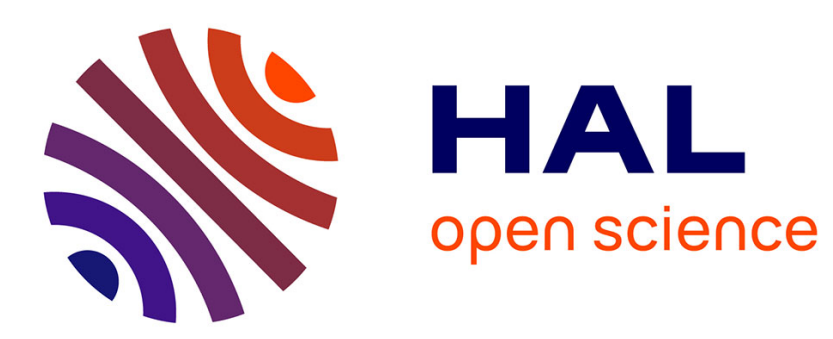

\title{
Some considerations on coupled physical-chemical transfer processes under microgravity conditions
}

Mohammed El Ganaoui, Roger Prud'Homme

\section{To cite this version:}

Mohammed El Ganaoui, Roger Prud'Homme. Some considerations on coupled physical-chemical transfer processes under microgravity conditions. High Technology Plasma Processes, 2004, 8, pp.333338. hal-02268398

\author{
HAL Id: hal-02268398 \\ https://hal.science/hal-02268398
}

Submitted on 3 Sep 2020

HAL is a multi-disciplinary open access archive for the deposit and dissemination of scientific research documents, whether they are published or not. The documents may come from teaching and research institutions in France or abroad, or from public or private research centers.
L'archive ouverte pluridisciplinaire HAL, est destinée au dépôt et à la diffusion de documents scientifiques de niveau recherche, publiés ou non, émanant des établissements d'enseignement et de recherche français ou étrangers, des laboratoires publics ou privés. 


\title{
SOME CONSIDERATIONS ON COUPLED PHYSICAL-CHEMICAL TRANSFER PROCESSES UNDER MICROGRAVITY CONDITIONS
}

\author{
M. El Ganaoui' ${ }^{1}$ R. Prud'homme ${ }^{2}$
}

\begin{abstract}
This paper is essentially devoted to researcher's interested by transfers with coupled physical and chemical problems occurring under microgravity conditions $(\mu \mathrm{g})$. Some illustrations about research conducted recently are described. The text informs also about two specific issues to be published soon illustrating particularly the enormous potential of fundamental and applied fluid mechanics and physics in space related to beneficial applications related to development of sciences and technologies.
\end{abstract}

\section{Microgravity}

Gravitation is well here, human beings feeling it everywhere on the earth. Nevertheless, $\mathrm{XVII}^{\text {th }}$ century was the beginning of the proof of the universality of this feeling, although the first questions about body's falling where asked since antiquity, about two millenaries ago. The gravity concept was first thought, then experimented. Mathematical translation of this concept did open new horizons and the Newtonian theory prevailed in physics during more than two centuries until the overthrow related to springtide of relativity.

During this long period before our era, experimentation accompanied the physicist in his study of microgravity. He tried to free himself from gravitation to perform his experiments, sometimes successfully without leaving the earth, but for short durations, for example as is the case of free-falling studies. He would certainly has dreamed b dispose of locations with no gravity during longer times for bis investigations. Presently, scientists have such locations at their disposal, and for long durations. For example, free falling can be observed during several weeks (Space project MICROSCOPE selected by CNES). The invention of space vehicles and artificial satellites has opened to human being new fields of investigation. One can travel inside interplanetary and interstellar spaces, approach heavenly bodies to observe them better, scrutinize our planet, and install telecommunications and observation satellites around the earth. The scientific instrumentation has been drastically enriched with these new means.

These gravity-free conditions are indeed realized even inside space stations. This is a direct result of the basic laws of classical mechanics and their expression in a reference frame, especially that of the space dwelling, which moves, as in vacuum, solely under the action of long-distance forces of attraction. Indeed, the frame of reference associated with these stations is of course non-Galilean. In principle, the gravity acceleration must be compensated exactly by that of the reference frame.

Beyond natural curiosity that gravity procures, the first pioneers of antiquity have studied microgravity especially for the induced phenomena, for instance those occurring in engines which were used at that time by craft men and engineers. Nowadays, one is especially interested by phenomena that gravity can mask, as in fluid media where diffusive transfer can be masked by natural convection [1-10].

\footnotetext{
${ }^{1}$ SPCTS, Université de Limoges UMR 6638 CNRS, -123 Albert Thomas-87060 Limoges, France.

${ }^{2}$ Université Pierre et Marie Curie/CNRS - 4 Place Jussieu -75252 Paris Cedex 05, France.
} 
To be free from gravity provides the fluid mechanician or physicist with a mean of avoiding buoyancy and its consequences, such as natural convection and density stratification which affect particularly hyper-compressible fluids. Attention is also paid at detecting signs of new physics, such as gravity waves, which may confirm general relativity theory.

Satellites and terrestrial facilities do not allow gravity to be completely eliminated, and some residual gravity remains. This is the reason why one speaks of micro-gravity rather than zerogravity. This residual acceleration is not uniform in time and space. Hence one speaks of gjitters to describe random acceleration variations, which in general hinder the experimenter. The micro-gravity quality as well as its duration are permanent requirements of the scientist working in microgravity. In short, spatial surrounding offers today a privileged situation for gravity law experimentation with a better precision and better protection against ail noises existing on the earth (such as for example seismic noise, ...).

\section{The microgravity tool and utilization examples}

Microgravity experimentations (drop towers, parabolic flights, sounding rockets and orbital stations) are interesting for certain fluid mechanic problems where density gradients are important and forced convection is not too high. One can there clarify certain situations becoming too complex due to the existence of Archimedean forces and reproduce ideal conditions corresponding to well known typical problems. In France, CNES and CNRS support these studies through research groups since 1992. Experimentation in microgravity, and associated theoretical and numerical supports, are remarkably interesting for basic research as well as for applications.

An example is that of fluids near their liquid-vapor critical points. In this state, a gas is as dense as a liquid, but as compressible and expandable as a gas, and it is a bad heat conductor. Any small local temperature or pressure variation causes big density changes which, on the ground, are sources of convective motions. On the contrary, zero-gravity allows avoiding these motions and performing better studies of, for instance, the heating of these fluids by contact with a wall. Experiments have been performed, which have sustained theoretical previsions indicating that the critical state furthered a new heat transport mode, that's more rapid than conduction, the "piston effect". These studies have been performed during more than ten years and new experiments are provided in the International Space Station (ISS). Chemical mixtures and boiling in critical regime will be particular topics. Engine domain (Ariane rocket cryogenic engine ${ }^{3}$, Diesel engine ${ }^{4}$, as well as organic waste treatment are in critical fluid application fields.

\footnotetext{
${ }^{3}$ Ariane IV missions for the future will present microgravity periods. Reignition of the engine will then be performed in unaccustomed conditions, for tanks, pipes, pumps, and the whole cryogenic engine. For example, cold putting of liquid hydrogen and oxygen pump will be accompanied by boiling near walls and the curve giving the heat transfer in function of temperature, which will be described in the direction of decreasing temperatures, will be different from that obtained on the ground level under $1 \mathrm{~g}$ acceleration. Boiling crisis will be differently located. Consequences of such changes must be provided, for example on the ignition delays.
}

${ }^{4}$ Example of supercritical. Supercritical fluid at $500{ }^{\circ} \mathrm{C}$ and $25 \mathrm{MPa}$ becomes a particularly good solvent for most organic compounds while inorganic ones do precipitate. Gaseous compounds, and especially oxygen, are equally solvable in large proportions in this medium. Then it is a medium where organic matter and oxidizer are well mixed, what makes the oscillation reaction extremely fast. Supercritical fluids, very compressible and expandable near die critical point, but also very dense, are 
Droplet vaporization and combustion is another example (sec illustrations §5). Generally, the size of droplets vaporized by the injectors is of order of one Micrometer [8] These droplets are little influenced by gravity and keep a spherical shape, that makes their study easier. But, due to their small size, they are not suitable for experimental observation. On the ground, larger droplets are distorted, and the emitted hot gases ascend unrelentingly, breaking then the spherical symmetry of the system. On the other hand, microgravity makes possible both realization and study of such millimeter large droplets. Experiments where performed in drop towers, airplane parabolic flights, sounding rockets, and are also provided for ISS. At present, studies deal with droplet lattices for a better understanding of droplets interaction when they are concentrated in dense clouds.

\section{State of the art in microgravity research}

The setting up of the International Space Station has been performed essentially without consulting the community of scientists, who has however been solicited for proposing experiments. Many of them have used this opportunity. the programs have been delayed for various reasons but have not been questioned until now.

National agencies play a dominant role in the direction and financing of research. In France, the Centre National d'Etudes Spatiales (CNES), together with the European Space Agency (ESA) play an increasing role. A CNES workshop on prospective projects takes place periodically (each five year), where research directions and priority themes are defined. Approximately 200 researchers work in the field of "Material Sciences in Microgravity", partially organized in the framework of a Research Group CNES/CNRS. Teams of the Centre National de la Recherche Scientifique (CNRS), of some Universities as well as others from the Commissariat à l'Energie Atomique (CEA) participate in discussions within this group. This division does not escape from the difficulties encountered in the financing of science and the employment of scientists.

In the following are given some characteristics of these activities, as they appear from preparation of the prospective seminary of the CNES in 2002.

- Floating object: Granular media and multiphase flows are studied in their fundamental aspects but also for applications. To understand flows with bubbles is certainly useful for circulation of fluids on board space vehicles. Vibration effects on fluids and granular material is a fundamental and applied topic.

- Convection, solidification, and crystal growth: Solid/liquid phase change is sensitive to gravity [5]. Natural convection occurs coupled to solidification front motion. The interfacial zone is often overly complex to describe. Indeed, front curvature and solid phase structure depend on several factors and it will be interesting to eliminate some of them due to gravity for a better understanding of solidification process. At the same time, it is especially useful to perform calculations with and without gravity effects. Process control by vibration or magnetic field is sometimes required to stabilize solidification fronts.

- Combustion and reactive media: Microgravity experiments are needed for fundamental and applied studies of droplet combustion, flame propagation on materials,

sensitive to gravity, in such a way that microgravity experimentation is necessary to understand and model their behavior. 
droplet or particle interaction during evaporation and combustion. This domain is related to the rocket engine technology and to the fires in microgravity environments [8].

- Critical phenomena: A new heat transport mode has been recently discovered by teams of the proposed network. It is called the "piston effect" [2]. Supercritical chemistry will be studied in DECLIC instrument which has been qualified for the ISS. Many potential applications are foreseeable for chemical industry, separation processes and combustion.

- Fluid interfaces: "Interfacial dynamics for understanding foams, emulsions and capsules" and "Interfacial Heat/Mass Transfer" are the titles of two network proposals where teams research CNES/CNRS group are implied. Boiling of liquid near solid surfaces is a real problem for the microgravity periods of $\mathrm{VINCI}^{5}$ engine for example.

\section{Context of this topical issue}

The Research Group CNES/CNRS «Transport Phenomena and Phase Transitions in Microgravity» (GDR $\left.\mathrm{N}^{\circ} 2258\right)^{6}$, named since a short time «Fundamental and Applied Microgravity» (MFA, GDR $\mathrm{N}^{\circ}$ 2799) includes around thirty teams, members of the Department 'Sciences for Engineers (SPI)' and 'Chemical Sciences' of CNRS, having many communications with the Atomic Energy Commissariat (CEA), which study the effect of gravity on systems including at least one fluid phase, on critical phenomena, chemistry (combustion, corrosion, ...) and the supercritical fluid dynamics, being interested by domains where fluid mechanics is closely mixed with chemistry. It includes also teams working on the solidification of transparent mediums, which belong to the CNRS Department Physical Sciences and Mathematics (SPM).

But the mission of MFA is also to ensure the cohesion of the community of laboratories utilizing microgravity ambiance, noticeably with leading scientific actions for promotion and diffusion of information (workshops, seminaries, colloquia) and developing the action all over Europe (action at two years). MFA prepares and provides commuting actions with space technologies (CNES, other GDR) and defines common actions with the Technical Competence Centres of CNES.

The Colloquium "Microgravity and Transfer" which took place September $3^{\text {rd }} 2003$ within the " $16^{\text {th }}$ French Congress of Mechanics" was principally devoted to the research topics of the GDR (Critical fluids, interfaces and phase change, two-phase flow, combustion, chemical reactivity, process control including vibrations and magnetic field.

25 specific papers have been presented. They reflect partly the work of the French scientific community on these topics and permit positioning them in the international context thanks to general talks of French and foreign invited speakers.

Our wish to provide a more extensive written record dedicated to the theme of transfers under conditions of microgravity in space and presenting the state of French knowledge of te mechanical sciences was received favourably and encouraged by colleagues of various disciplines. Alter due considerations, it has been decided to implement the publication of two special issues based on the detailed papers which were submitted.

\footnotetext{
${ }^{5}$ http://www. snecma.com/fr/group/markets/launchers/vinci/index.php

${ }^{6} \mathrm{http} / / /$ web.ccr.jussieu.fr/P2TPM/
} 
The matter is a topical issue of « Mécanique et Industries » (M \& I), the journal of the French Mechanics, as well as a "Dossier Mécanique » of the Comptes Rendus de l'Académie des Sciences [6]. For M\&I, have been retained papers with a potentially rich applied character [7].

\section{Some illustrations : heat and mass transfer in microgravity}

\section{1 Vaporization near the critical point}
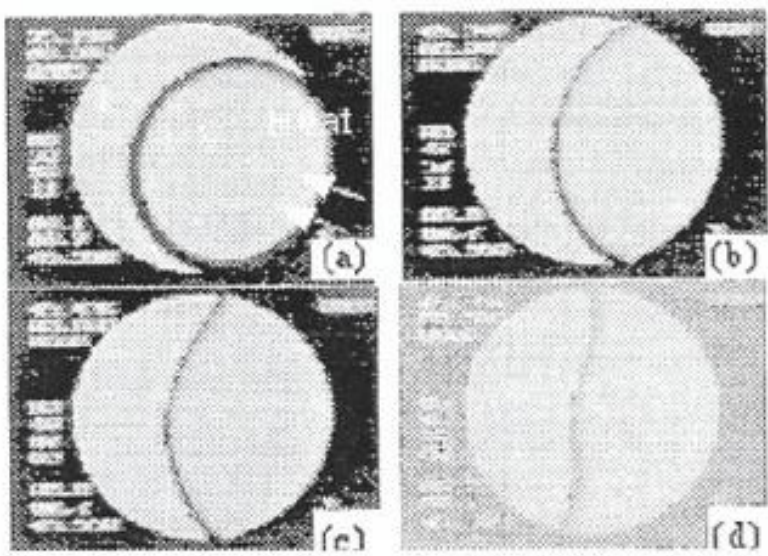

Checking of an anomaly. The contact angle liquid/vapor/solid denotes an inversion of wetting (the vapor seems to wet the wall). This phenomenon may result from vapor recoil. From : Y. Garrabos, C. Chabot, R. Wunenburger, J.P. Delville and D. Beysens Critical boiling phenomena observed in microgravity, J Chim. Phys. 96 (1999) 1066-1073.

\section{2 Candle flame}
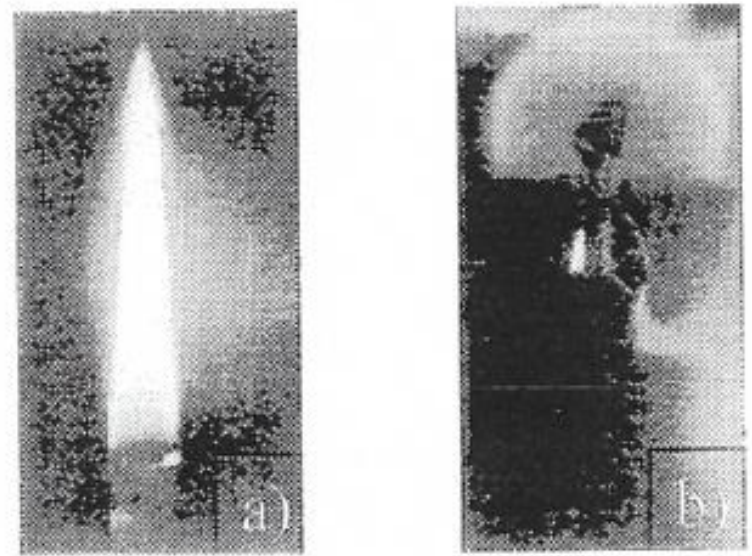

Candle flame a) On the ground b) In microgravity. The yellow color characterizes the presence of soot. From: F.B. Carleton, F. J. Weinberg, Electric field-induced flame convection in the absence of gravity, in Combustion experiments during KC-135 parabolic flights, ESA SP-1113, ISBN 92-9092-008-4 (1989).

\section{Acknowledgments}

To professor Pierre FAUCHAIS for his invitation to include this synthesis in the field in the Journal of High Temperature Material Processes.

\section{Bibliography}

1. R. Bonneville "la micropesanteur " Pour la Science, 152, 102-111 (1990)

2. B. Zappoli "Les Sciences de la matière en micropesanteur", to be published, Mécanique \& Industries, Vol. 5, No5, 2004. 
3. R. Prud'homme «L'intérêt de l'outil Microgravité» pour la mécanique des fluides et ses applications », Mécanique \& Industries, Vol 5, N³, 2004.

4. R. Prud'homme, D. Langevin, O. Faivre, Eds. Sciences de la Matière et Microgravité, Colloque 86, J. Phys. IV France, 11(2001).

5. R. Prud'homme, M. El Ganaoui. On some basic considerations of solid/liquid transition models under microgravity Environment. special issue of Int. J of Materials and Product Technology on 'Crystal Growth of Semiconductors from the liquid phase'. Ed. S. Dost, [In Press].

6. R. Prud'homme \& M. El Ganaoui (Guest Eds.), Microgravity, Comptes Rendus Académie des Sciences Mecanique t. 332, fasc. 5-6, Elsevier, 2004.

7. M. El Ganaoui, R. Prud'homme (Ouest Eds.), Microgravité et Transferts: de la recherche fondamentale à l'application industrielle, Revue Mécanique et Industrie, numéro thématique, à paraître 2004.

8. R. Prud'homme, Combustion en micropesanteur. Le Point sur. Review Paper, C.R. Académie des Sciences, Série II, t. 329, N³, mars 2001. Fascicule b. Mécanique.

9. B. Zappoli \& R. Prud'homme, EDS.- Journées d'Oléron du GDR PR2M. Journal de Chimie Physique et de Physico-chimie Biologique, Tome 96 - № 6-Juin 1999,(179 pages).

10. La Gravitation: 1'univers sous influence. Dossier pour la science Hors Série. Janvier/Avril 2003. 